\title{
Assessment of Baseline Anxiety and Effect of Nursing Intervention on Post-Operative Anxiety among Surgical Patients of Obafemi Awolowo University Teaching Hospitals Complex, Ile Ife, Nigeria
}

Adetunji Oluseye Adetayo $^{1^{*}}$ and Salawu Rasidi Akinade ${ }^{2}$

${ }^{1}$ Obafemi Awolowo University Teaching Hospitals Complex, Ile-Ife Osun State, Nigeria

${ }^{2}$ Department of Adult Health, Babcock University School of Nursing, Ilishan Remo, Ogun State, Nigeria

"Corresponding author: Adetunji Oluseye Adetayo, Obafemi Awolowo University Teaching Hospitals Complex, Ile-lfe Osun State, Nigeria, Tel: +2348063239911; Email: tunjioluseye4ever@yahoo.com

Received date: Feb 12, 2019; Accepted date: Mar 07, 2019; Published date: Mar 14, 2019

Copyright: @ 2019 Adetayo AO, et al. This is an open-access article distributed under the terms of the Creative Commons Attribution License, which permits unrestricted use, distribution, and reproduction in any medium, provided the original author and source are credited.

\begin{abstract}
Surgical patients perceived the day of surgery as highly terrifying in their lives. Patients manifest different levels of anxiety states in relation to what is expected in future and these are associated with many factors which may be type and extent of the proposed surgery, gender, age, previous surgical experiences, and personal tendency for unpleasant events. The study aimed to assess baseline anxiety and effect of nursing intervention on post-operative anxiety states among surgical patients.
\end{abstract}

Two-group pre-test, post-test quasi-experimental study was adopted and thirty surgical patients were included. Sample size was determined using Leslie Kish formula and purposive sampling technique was adopted to select 15 surgical patients in to the experimental and control groups respectively. The intervention group had structured nursing information but control group did not. Data was processed using statistical package for social science version 21. Two research questions were answered using descriptive statistics of percentages and one hypothesis was tested using inferential statistics of student t-test at 0.05 level of significance.

This study shows that anxiety states are common to all surgical patients. The surgical patients (in both experimental and control groups) (33\%) experienced high anxiety state preoperatively. The percentage reduction in the number of respondents that expressed high level of anxiety state in the experimental group ( $40 \%$ reduced to $26.7 \%)$ as they move from preoperative to postoperative periods as compared with the control group $(26.7 \%$ increased to $33.3 \%$ ). This shows the relative impart of the nursing intervention, but the mean differences of anxiety of the experimental group was 0.08 ; while that of the control group was 0.15 respectively. Result reveals no significant difference in anxiety level among participants in the experimental and control groups $(p=0.514)$.

Surgical patients should be assessed of anxiety states in the perioperative environment. The information needed and provided to each surgical patient should be assessed and patient-centered to prevent failure of preoperative information.

Keywords: Purposive sampling; Post-operative anxiety; Quasiexperimental study; Surgical patients

\section{Introduction}

Surgery is one of the major life changes that cause anxiety. Hospitalization provokes anxiety in the patient admitted for surgery, even in the absence of disease. Stress resulting from protracted anxiety may eventually endanger the client if not discovered early and slowdown recovery [1-4]. Surgery can trigger a panic attack in a patient who is prone to anxiety. The preparative care of surgical patients becomes very challenging with the increasing existence of anxiety before surgery. Anxiety experience is common to most patients awaiting elective surgery and generally seen as normal response [5].

Surgical patients perceived the day of surgery as highly terrifying in their lives. Patients manifest anxiety with varying degrees in relation to what is expected in future and these are associated with many factors which may be type and extent of the proposed surgery, gender, age, previous surgical experiences, and personal tendency for unpleasant events [6]. The intervention for employed by the healthcare providers has been found to promote, comfort, and favorable surgical outcomes. Nurses and other healthcare givers needs to know patients who are prone to anxiety in the population in order to reduce the occurrence of anxiety resulting from surgery.

The observation of the researcher in the past 10 years of clinical practice at the perioperative environment was the apparent uneasiness, confusion and anxious appearance demonstrated by the surgical patients coming for procedures in the operating suites. A number of these patients' responses to their surgical procedures were undesirable. Preoperative anxiety was reported as one of the factors causing delayed discharge following a day surgery [7]. According to Agarwal et al. [8] and Pritchard et al. [9] greater amount of analgesic and anaesthetic are required with increased postoperative pain and extended hospital stay in patients with anxiety. Delayed wound healing has been associated with anxiety and response to stress in different research studies [10-12]. 
Citation: Adetayo AO, Akinade SR (2019) Assessment of Baseline Anxiety and Effect of Nursing Intervention on Post-Operative Anxiety among Surgical Patients of Obafemi Awolowo University Teaching Hospitals Complex, lle Ife, Nigeria. J Nurs Care 8: 477. doi: $10.4172 / 2167-1168.1000477$

Page 2 of 4

Anxieties of patients in general have been reported to be linked with poor information. Anxieties, fear, challenges of communication have been found to intensify the experience of pain by the patients [13]. According to Mitchell et al. [14] the pre-operative anxiety experienced by surgical patients before general anaesthesia is common. Therefore, the effectiveness of preoperative nursing intervention on the relief of anxiety state among surgical patients needs to be studied by evaluating the different levels in patient's care in the context of the Nigerian health facilities and many cultural diversities.

\section{Materials and Methods}

\section{Study design}

The study adopted two groups pre - test post - test quasiexperimental design to evaluate nursing intervention on post-operative anxiety among surgical patients in Obafemi Awolowo University Teaching Hospitals Complex, Ile- Ife, Osun State, Nigeria between February $10^{\text {th }}$ to March $15^{\text {th }}, 2017$.

\section{Population}

The population was 60 adult surgical patients admitted and booked for abdominal surgery in Obafemi Awolowo University Teaching Hospitals Complex, Ile- Ife, Osun State which was obtained from the previous one month record. Adult surgical patients admitted and booked for abdominal surgery were included in the study. Adult surgical patient who were unconscious and unwilling to participate in the study were excluded.

\section{Sample size and sampling technique}

Sample size was determined using Leslie Kish formula and purposive sampling technique was adopted to select 30 adult surgical patients (15 surgical patients who formed the experimental group and 15 patients who formed the control group).

\section{Instrumentation}

The instrument utilized for data collection were a developed demographic data form consisting of four items and used to collect data about the surgical patients demographic data. A standardized State-Trait Anxiety Inventory (STAI) [15] was adopted for the study. The state-Anxiety Questionnaire consists of 20 statements on a 4-point scale and it is used to assess momentary anxiety. According to Speilberger et al. [15] STAI has been evaluated for its reliability in terms of stability and internal consistency for test-retest correlations and Alpha coefficients using the Kuder Richardson formula. Low values of test-retest correlations for State anxiety scale were reported ranging between 0.54 and 0.60 . According to Calvin et al. [16] the coefficient alpha for state anxiety scale as an established value for the study sample as 0.90 .

\section{Procedure for data collection}

The procedure for data collection involved three phases:

Phase 1: It involved meeting with the recruited surgical patients individually where information about the purpose, course and potential benefits of the study was discussed. Consent was obtained from each surgical patient in both the experimental and control group after which the demographic data of each surgical patients was obtained using the developed demographic data form. Data on preintervention anxiety state levels were obtained using the STAI Questionnaire in which patient was asked to rate the anxiety state levels experienced on the scale 12 hours after surgery (Table 1).

Phase 2: Surgical patients in the experimental group were exposed to structured preoperative teaching music therapy and guided imagery 12 hour after surgery over the period of 12 hours while surgical patients in the control group were not exposed to the nursing interventions.

Phase 3: Data on post- intervention anxiety level was obtained 24 hours after surgery from individual surgical patients in both the experimental and the control group using the STAI Questionnaire.

\begin{tabular}{|c|c|c|c|}
\hline \multirow[b]{2}{*}{ Age: (in grouped years) } & Experimental Group & $\begin{array}{l}\text { Control } \\
\text { Group }\end{array}$ & Total \\
\hline & $n(\%)$ & $n(\%)$ & $n(\%)$ \\
\hline $25-34$ years & $4(26.8)$ & $6(40)$ & $10(33.3)$ \\
\hline $35-44$ years & $7(46.8)$ & $2(13.3)$ & $9(30.0)$ \\
\hline $45-54$ years & $2(13.3)$ & $2(13.3$ & $4(13.3)$ \\
\hline $55-64$ years & $0(0.0)$ & $4(26.8)$ & $4(13.3)$ \\
\hline $65-74$ years & $1(6.7)$ & $0(0.0)$ & $1(3.3)$ \\
\hline $75-84$ years & $1(6.7)$ & $1(6.7)$ & $2(6.7)$ \\
\hline Mean age $\pm S D$ & $43.87 \pm 13.6$ & $45.2 \pm 15.2$ & $\begin{array}{l}44.53 \quad \pm \\
14.1\end{array}$ \\
\hline \multicolumn{4}{|l|}{ Gender } \\
\hline Male & $3(20)$ & $5(33.2)$ & $8(26.7)$ \\
\hline Female & $12(80)$ & $10(66.8)$ & $22(73.3)$ \\
\hline \multicolumn{4}{|l|}{ Marital Status } \\
\hline Single & $2(13.3)$ & $2(33.3$ & $4(13.3)$ \\
\hline Married & 13(86.6) & 13(86.6) & $26(86.7)$ \\
\hline \multicolumn{4}{|l|}{ Educational Background } \\
\hline Primary Education & $4(26.8)$ & $1(6.7)$ & $5(16.6)$ \\
\hline Secondary Education & $7(46.8$ & $5(33.2)$ & $12(40.0)$ \\
\hline OND & $2(13.2)$ & $3(20.0)$ & $5(16.6)$ \\
\hline HND & $0(0.0)$ & $2(13.2)$ & $2(6.6)$ \\
\hline First Degree and above & $2(13.2)$ & $4(26.6)$ & $6(20.0)$ \\
\hline \multicolumn{4}{|l|}{ Ethnicity } \\
\hline Yoruba & 14(93.3) & $12(80.0)$ & $26(88.3)$ \\
\hline \multirow[t]{2}{*}{ Igbo } & $1(6.7)$ & $3(20.0)$ & $4(11.7)$ \\
\hline & $15(100.0)$ & $15(100.0)$ & $30(100.0)$ \\
\hline
\end{tabular}

Table 1: Frequency and percentage showing demographic data of surgical patients. 
Citation: Adetayo AO, Akinade SR (2019) Assessment of Baseline Anxiety and Effect of Nursing Intervention on Post-Operative Anxiety among Surgical Patients of Obafemi Awolowo University Teaching Hospitals Complex, lle Ife, Nigeria. J Nurs Care 8: 477. doi: $10.4172 / 2167-1168.1000477$

Page 3 of 4

\section{Method of data analysis}

Data gathered from surgical patients were processed using statistical package for social science (SPSS) version 21. Frequency table was constructed and data were expressed on it. Two research questions were answered using descriptive statistics of percentage and one hypothesis was tested using inferential statistics of student $t$ - test at 0.05 level of significance.

\section{Ethical Consideration}

Ethical clearance was obtained from the Babcock University Health Research Ethics Committee (BUHREC) with clearance number BUHREC604/16. Permission was also obtained from the management of Obafemi Awolowo University Teaching Hospitals Complex, Ile-Ife, Osun State, Nigeria before the study was conducted. The surgical patients were ad equally informed about the study and consent was obtained before data was collected. Information obtained from the surgical patients was kept confidential and the right to withdraw from the study at any point by the surgical patients was respected with no consequences suffered. No harm was suffered by the surgical patients during the research study. Post research benefit includes improvement in the management of pre -operative and post-operative anxiety states among surgical patients by nurses.

The analysis in Table 2 revealed that the baseline anxiety level among the study participants between the experimental group and the control group. The results showed that surgical patients experienced high baseline levels of anxiety in the experimental group (40\%) and the control group (26.7\%).

Table 2 also showed that $60 \%$ of the surgical patients had low level anxiety and $26.7 \%$ had high level anxiety in experimental group during the postoperative period. $53 \%$ of the control group had low level of anxiety while $33 \%$ had high level of anxiety.

The mean differences of anxiety of the experimental group was 0.08 ; while that of the control group was 0.15 respectively.

\begin{tabular}{|c|c|c|c|c|c|c|}
\hline & & & \multicolumn{2}{|l|}{ Surgical Patients } & \multirow[t]{2}{*}{ Total f(\%) } & Statistic \\
\hline & & & Experimental $f(\%)$ & Control $f(\%)$ & & \multirow{5}{*}{$X 2=1.329 d f=2 p=0.514$} \\
\hline \multirow[t]{4}{*}{ Pre-Operative } & \multirow[t]{3}{*}{ Baseline Level of Anxiety } & Low & $4(26.7)$ & $7(46.7)$ & $11(36.7)$ & \\
\hline & & Moderate & $5(33.3)$ & $4(26.7)$ & $9(30.0)$ & \\
\hline & & High & $6(40.0)$ & $4(26.7)$ & $10(33.3)$ & \\
\hline & & Mean \pm SD & $1.74 \pm 0.49$ & $1.79 \pm 0.49$ & $1.77 \pm 0.5$ & \\
\hline & & & \multicolumn{2}{|l|}{ Surgical Patients } & Total & Statistic \\
\hline & & & Experimental & Control & & \\
\hline \multirow[t]{4}{*}{ Post-operative } & Level of Anxiety & Low & $9(60.0 \%)$ & $8(53.3 \%)$ & $17(56.7 \%)$ & \multirow[t]{4}{*}{$X 2=0.170 d f=2 p=0.919$} \\
\hline & & Moderate & $2(13.3 \%)$ & $2(13.3 \%)$ & $4(26.7 \%)$ & \\
\hline & & High & $4(26.7 \%)$ & $5(33.3 \%)$ & $9(30.0 \%)$ & \\
\hline & & Mean \pm SD & $1.66 \pm 0.5$ & $1.64 \pm 0.46$ & $1.60 \pm 0.5$ & \\
\hline
\end{tabular}

Table 2: Baseline anxiety and post-operative anxiety among surgical patients.

\section{Hypothesis Testing}

H01 - There is no significant relationship between nursing interventions for the relief of preoperative anxiety among surgical patients (Table 3).

\begin{tabular}{|l|l|l|l|}
\hline Statistics & $\mathbf{X 2}$ & $\mathbf{d f}$ & $\mathbf{p}$ \\
\hline & 1.329 & 2 & 0.514 \\
\hline
\end{tabular}

Table 3: Statistical relationship between nursing intervention and relief of anxiety.

\section{Discussion}

There were more surgical patients between 25-34 years in the hospital during data collection. This implies that more surgical patients between 25-34 years develops abdominal disease conditions requiring surgery and reports to the hospital. This finding disagrees with previous quasi-experimental study in which there were more surgical patients between 35-44 years during data collection [17]. There were more female surgical patients during data collection. This implies that more female surgical patients reports to the hospital for treatment with abdominal disease conditions requiring surgery. This finding supports previous quasi-experimental study in which there were more female surgical patients during data collection [18]. There were more married surgical patients during data collection. This implies that more married surgical patients' reports to the hospital for treatment with abdominal disease conditions requiring surgery. This finding supports previous quasi-experimental study in which there were more married surgical patients during data collection [19]. There were more tertiary school certificate holders among surgical patients in the hospital during data collection. This implies that more surgical patients with tertiary school certificate develops abdominal disease conditions requiring surgery and reports to the hospital. This finding agrees with previous quasiexperimental study in which there were more tertiary school certificate holders among surgical patients in the hospital during data [17]. This study found that anxiety states are common to all surgical patients, $33 \%$ of the surgical patients (in both experimental and control groups) 
Citation: Adetayo AO, Akinade SR (2019) Assessment of Baseline Anxiety and Effect of Nursing Intervention on Post-Operative Anxiety among Surgical Patients of Obafemi Awolowo University Teaching Hospitals Complex, lle Ife, Nigeria. J Nurs Care 8: 477. doi: 10.4172/2167-1168.1000477

Page 4 of 4

experienced high anxiety state preoperatively. This corroborates the opinions of Ebirim et al. [1] as well as Yilmaz et al. [4] that Hospitalization associated with surgery is one of life changes that causes anxiety. According to Akinsolure et al. [19] 51\% incidence of high anxiety level among surgical patients occurred in the same health facility. Although, the sample size of their study $(n=51)$ was slightly higher than the current study ( $n=30)$. Another study found that $25 \%$ of surgical patients experienced high anxiety state levels [10]. A prevalence of preoperative anxiety of $34.4 \%$ was reported by Ebirim et al. [1] in a study at Niger-Delta region of Nigeria (Port Harcourt) using a visual analogue scale. Regarding the prevalence rate of preoperative anxiety, it is a common opinion that many elective surgical patients experience a level of anxiety [20].

The mean baseline levels (1.77) of preoperative anxiety state of the study respondents were higher before surgery, this was consistent with the study by Ebirim et al. [1] who reported a preoperative mean score of 42.72 , although the baseline mean anxiety level of this study was not as high as the one reported.

The percentage reduction in the number of respondents that expressed high level of anxiety state level in the experimental group (40\% reduced to $26.7 \%$ ) as they move from preoperative to postoperative periods as compared with the control group $(26.7 \%$ increased to $33.3 \%$ ). This showed the relative impart of the nursing intervention. Although, the relative impart of nursing was not statistically significant $(p=0.919, d=2)$, there was an observable difference in the patients' responses. This study supported Goebel et al. [2] and Miner et al. [13] who reported inverse association of anxiety and education. Also, Giraudet-Le Quintrec et al. [19] in an interventional study for comparison of the collaborative multidisciplinary information session with the routine method of verbal information on preoperative and postoperative anxiety among surgical patients booked for total hip arthroplasty reported that the experimental group were significantly less anxious preoperatively following the teaching $(\mathrm{P}=0.01)$.

The researcher observed that the information provided to each individual patient should be assessed and patient-centered. According to Chumbley et al. [20] little effects is provided by detailed preoperative information with either an interview or information leaflet. It was reported that patients are better informed and less confused. The possible reasons for the failure of preoperative information to yield benefits was its inability to quickly change patients' long-held perception and beliefs [20].

\section{Conclusion}

The assessment of baseline anxiety and effect of nursing intervention on post-operative anxiety among surgical patients of Obafemi Awolowo University Teaching Hospitals Complex, Ile-Ife, Osun State, Nigeria was the focus of the study.

The study found out that the experience of anxiety states among surgical patients is a common phenomenon in the perioperative environment. The mean baseline levels of preoperative anxiety state of the study respondents were higher before surgery. The percentage reduction in the number of respondents that expressed high level of anxiety state level in the experimental group as they move from preoperative to postoperative periods as compared with the control group showed the relative impart of the nursing intervention. There was an observable difference in the patients' responses to nursing intervention.

The baseline levels of preoperative anxiety state is a crucial indicator of determining quality of care. The information needed and provided to each individual surgical patient should be assessed and patientcentered to prevent failure of preoperative information.

\section{References}

1. Ebirim L, Tobin M (2010) Factors responsible for pre-operative anxiety inelective surgical patients at a University Teaching Hospital: A pilot study. The Internet Journal of Anesthesiology 2: 1.

2. Goebel S, Kaup L, Mehdorn HM (2011) Measuring preoperative anxiety in patients with intracranial tumors. J Neurosurg Anesthesiol 23: 297-303.

3. Swindale JE (2004) The nurse's role in giving pre-operative information to reduce anxiety in patients admitted to hospital for elective minor surgery. J Adv Nurs 14: 899-905.

4. Yilmaz M, Sezer H, Gürler H, Bekar M (2011) Predictors of preoperative anxiety in surgical inpatients. J Clin Nurs 21: 956-964.

5. Jawaid M, Mushtaq A, Mukhtar S, Khan Z (2011) Preoperative anxiety before elective surgery. Neurosciences 12: 145-148.

6. Ping G, Linda E, Antony A (2012) A preoperative education intervention to reduce anxiety and improve recovery among Chinese cardiac patients: A randomized controlled trial. Int J Nurs Stud 49: 129-137.

7. Vadivelu N, Mitra S, Narayan D (2010) Recent advances in postoperative pain management. Yale J Biol Med 83: 11-25.

8. Agarwal A (2005) Acupressure for prevention of pre-operative anxiety: a prospective, randomised, placebo controlled study. Anaesthesia 10: 978-981.

9. Pritchard MJ (2011) Using the hospital anxiety and depression scale in surgical patients. Nursing Standard 25: 35-41.

10. Marucha PT, Kiecolt-Glaser JK, Favagehi M (1998) Mucosal wound healing is impaired by examination stress. Psychosom Med 60: 362-365.

11. Padgett DA, Marucha P, Sheridan JF (1998) Restraint stress slows cutaneous wound healing in mice. Brain Behav Immun 12: 64-73.

12. Miner D (1990) Preoperative outpatient education. Nursing Manag 21: 27-29.

13. Mitchell M (2010) General anaesthesia and day-case patient anxiety. J Adv Nurs 66: 1059-1071.

14. Speilberger CD (1983) Manual for the State-trait Anxiety Inventory (STAI; Form Y). Palo Alto, Consulting Psychologist Press, California.

15. Calvin RL, Lane PL (1999) Perioperative Uncertainty and state anxiety of orthopaedic surgical patients. Orthop Nurs 18: 61-69.

16. Pamela E, Macintyre A, Stephan AS (2015) Acute pain management: A Practical Guide. (4th edn), USA.

17. Lorentzen V, Hermansen IL, Botti M (2011) A prospective analysis of pain experience, beliefs and attitudes, and pain management of a cohort of Danish surgical patients. Eur J Pain 16: 278-288.

18. Akinsolure A, Owojuyigbe AM, Faponle AF, Fatoye FO (2015) Assessment of preoperative and postoperative anxiety among elective major surgical patients in a Tertiary institution in Nigeria. Middle East J Anaesthesiol 23: 2.

19. Giraudet-Le Quintrec JS, Coste J, Vastel L (2003) Positive effect of patient education for hip surgery: a randomized trial. Clin Orthop Relat Res 414: $112-120$.

20. Chumbley GM, Ward L, Hall GM, Salmon P (2004) Pre-operative information and patient-controlled analgesia: much ado about nothing. Anaesthesia 59: 354-358. 